\title{
Using biochar from spent coffee grounds to treat pollution in livestock wastewater
}

\author{
Huong Thu Thi Tran 1,*, Tong Xuan Nguyen ${ }^{2}$, Yen Hai Thi Trinh ${ }^{1}$, Hang Thi To ${ }^{1}$, \\ Huyen Thanh Thi Dang ${ }^{1}$, Linh Thuy Thi Vu ${ }^{1}$, Phuong Thi Nguyen ${ }^{1}$, Thuy Thu Dinh ${ }^{3}$ \\ 1: Faculty of Environment, Hanoi University of Mining and Geology, Vietnam \\ 2: Institute of Environmental Science, Engineering and Management, Industrial University of Ho Chi Minh \\ City, Vietnam \\ 3: Microbiology Laboratory, Quatest 1, Directorate for Standard Metrology and Quality, Vietnam
}

\section{ARTICLE INFO}

Article history:

Received 18th Aug. 2020

Revised 03rd Sept. 2020

Accepted 31 ${ }^{\text {st }}$ Oct. 2020

\section{Keywords:}

Biochar,

COD,

Spent coffee grounds, Treatment efficiency, TSS.

\section{ABSTRACT}

Four types of biochar material synthesized from spent coffee grounds by slow pyrolysis process CF1 (500 $\left.{ }^{\circ} \mathrm{C} / 0.5 \mathrm{~h}\right) ; \mathrm{CF} 2$ (500 $\left.\mathrm{C} / 1.5 \mathrm{~h}\right) ; \mathrm{CF} 3$ $\left(500^{\circ} \mathrm{C} / 3 \mathrm{~h}\right) ; \mathrm{CF} 4\left(500^{\circ} \mathrm{C} / 6 \mathrm{~h}\right)$ is studied to treat two pollution parameters (COD and TSS) in livestock wastewater. Material characteristics were determined by SEM, EDX and BET methods. The results showed that the 4 samples of biochar materials were structured fiber clearly, the interplanar spacing which corresponds to the lattice plane. The $C$ content in the biochar sample is higher than the initial raw material sample; the highest value recorded reaches $90.61 \%$ C (CF2). $100 \mathrm{~mL}$ of the original livestock waster water is filtered through columns with $4 \mathrm{~g}$ of biochar CF1CF4 during reaction times varied from $0 h, 1 h, 4 h$ and $8 h$, the COD treatment efficiency and adsorption content of CF4 sample is highest of $96.41 \%$ and $188 \mathrm{mg} / \mathrm{g}$ after $8 \mathrm{~h}$, and the lowest value is $76.67 \%$ and 149.5 $\mathrm{mg} / \mathrm{g}$ after $1 \mathrm{~h}$ recorded in CF3 sample, however the COD value after treatment is still higher from 1.2 to 1.46 times than Vietnamese standard 62: 2016/MONRE - national technical regulation on the effluent of livestock. The CF3 material samples have the highest TSS treatment efficiency and adsorption content of $95.19 \%$ and $6.425 \mathrm{mg} / \mathrm{g}$ after $8 \mathrm{~h}$ and the lowest of $66.78 \%$ and $4.575 \mathrm{mg} / \mathrm{g}$ recorded in CF1 samples after $1 \mathrm{~h}$, response the requirements ofQCVN 62: 2016/MONRE. The results showed that biochar is a potential sorbent to removed pollutants from waste water.

Copyright (C) 2020 Hanoi University of Mining and Geology. All rights reserved.

${ }^{*}$ Corresponding author

E-mail: huonghumg@gmail.com

DOI: 10.46326/JMES.2020.61(5).15 


\title{
Tạp chí Khoa học Kỹ thuật Mỏ - Địa chất
}

Trang điện tử: http://tapchi.humg.edu.vn

\section{Nghiên cứu sử dụng than sinh học tổng hợp từ bã cà phê để xử lý ô nhiễm trong nước thải chăn nuôi}

\author{
Trần Thị Thu Hương ${ }^{1,}{ }^{*}$, Nguyễn Xuân Tòng ${ }^{2}$, Trịnh Thị Hải Yến ${ }^{1}$, Tô Thị Hằng 1 , \\ Đặng Thị Thanh Huyền 1, Vũ Thị Thùy Linh 1, Nguyễn Thị Phương 1, Đinh Thu \\ Thủy ${ }^{3}$ \\ ${ }^{1}$ Khoa Môi trường, Trường Đại học Mỏ Đị chất, Việt Nam \\ 2 Viện Khoa học Công nghệ và Quản lý Môi trường, Trường Đại học Công nghiệp Tp Hồ Chí Minh, Việt Nam \\ ${ }^{3}$ Phòng thử nghiệm vi sinh, Trung tâm kỹ thuật Tiêu chuẩn Đo lường Chất lượng 1, Tổng cục tiêu chuẩn đo \\ lường chất lượng quốc gia, Việt Nam
}

\begin{tabular}{|c|c|}
\hline HÔNG TIN BÀI BÁO & TÓM TẮT \\
\hline $\begin{array}{l}\text { Quá trình: } \\
\text { Nhận bài 18/08/2019 } \\
\text { Sứa xong 03/09/2020 } \\
\text { Chấp nhận đăng 31/10/2020 } \\
\text { Từ khóa: } \\
\text { Bã cà phê, } \\
\text { COD, } \\
\text { Hiệu suất xử lý, } \\
\text { Than sinh học, } \\
\text { TSS. }\end{array}$ & 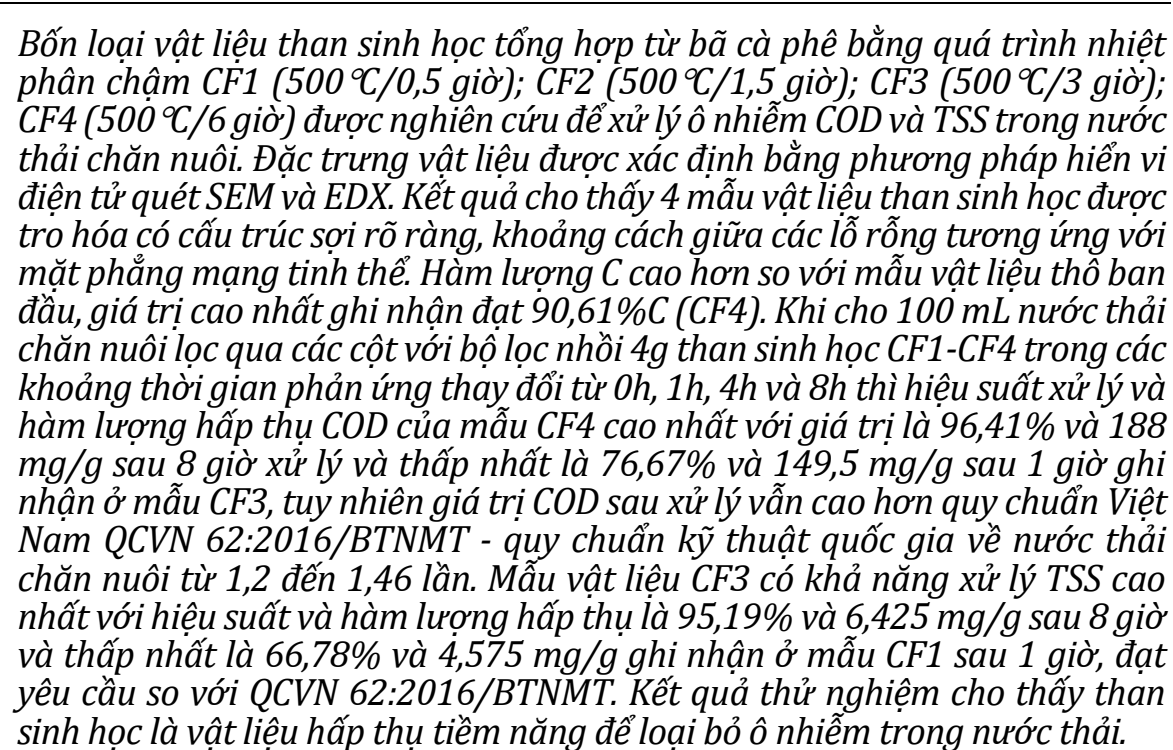 \\
\hline
\end{tabular}

(C) 2020 Trường Đại học Mỏ - Địa chất. Tất cả các quyền được bảo đảm.

*Tác giả liên hệ
E - mail: huonghumg@gmail.com
DOI: 10.46326/JMES.2020.61(5).15

\section{Mở đầu}

Việt Nam là nước nông nghiệp có khối lượng xuất khẩu cà phê lớn thứ hai trên thế giới (sau Brazil). Tổng lượng tiêu thụ nội địa cho cà phê là 60.000 tấn/năm, trong đó cà phê hòa tan chiếm 
khoảng 19.000 tấn, cà phê rang/xay chiếm 35.000 tấn, phần còn lại là cà phê rang/xay không nhãn hiệu (Truong Hong, 2018). Với việc sản xuất và tiêu dùng cà phê trên thế giới ngày càng tăng và khoảng 50\% sản lượng cà phê nhân được sử dụng để chế biến thành cà phê hòa tan thì sẽ có hơn 4,4 triệu tấn bã cà phê thải ra từ ngành công nghiệp này (Truong Hong, 2018). Bã cà phê là vật liệu lignocellulose có khả năng tách kim loại nặng và thuốc nhuộm trong nước dựa trên cấu trúc xốp và thành phần cellulose của chúng. Các nhóm hydroxyl và carboxyl trên bề mặt vật liệu carbonate đóng vai trò quan trọng trong trao đổi ion và hiệu quả xử lý chỉ ra rằng sự hấp thụ các chất ô nhiễm phụ thuộc vào các nhóm cực trên bề mặt vật liệu carbonate (Hirata và nnk., 2002). Trong nhiều thập kỷ qua, các nhà khoa học đã thực hiện các nghiên cứu về bã cà phê đã qua sử dụng và chứng minh rằng vật liệu này có đặc tính hấp phụ đáng kể, không chỉ kim loại nặng và các hợp chất hữu cơ độc hại trong nước mà còn hấp phụ cả khi carbon dioxide (Hirata và nnk., 2002).

Than sinh học hay còn gọi là biochar là một loại vật liệu cacbon chi phí thấp được sản xuất từ các loại phế, phụ phẩm nông nghiệp như phế phẩm trong sản xuất, chế biến gỗ, các loại cây nhỏ và vật liệu tổng hợp (Chen và nnk., 2011; Lehmann và Johannes, 2007; Pan và nnk., 2013). Than sinh học được tạo ra bởi quá trình nhiệt phân và có diện tích bề mặt lớn (từ 500 tới $2500 \mathrm{~m}^{2} / \mathrm{g}$ ). Do diện tích bề mặt lớn, than sinh học có nhiều vị trí có khả năng hấp thụ và trao đổi ion cao, do đó nó có khả năng lưu giữ các chất ô nhiễm (Chen và nnk., 2011; Lehmann và Johannes, 2007; Pan và nnk., 2013). Than sinh học tổng hợp từ nhiều nguồn phụ phẩm như bã cà phê (Tsai và Wen Tien, 2017), cây tre (Yang và nnk., 2014), vỏ trấu (Kizito và nnk., 2015), chất thải nông nghiệp (Liu và nnk., 2015) và chất thải rắn đô thị (Sumalinog và nnk., 2018). Trong đó, than sinh học tổng hợp từ bã cà phê có nhiều ư điểm hơn cả về nguồn nguyên liệu sản xuất ban đầu và về đặc trưng vật liệu.

Tại Việt Nam, tổng khối lượng chất thải chăn nuôi là khoảng 73 triệu tấn/năm, trong đó chất thải của lợn chiếm khoảng 24,38 triệu tấn/năm, tương đương $33,4 \%$ và $25-30$ triệu $\mathrm{m}^{3}$ chất lỏng (phân lỏng, nước tiểu và nước rửa). Trong đó, khoảng $50 \%$ chất thải rắn (36,5 triệu tấn), 80\% chất thải lỏng $\left(20 \div 24\right.$ triệu $\left.\mathrm{m}^{3}\right)$ thải trực tiếp ra môi trường hoặc không được xử lý sẽ gây ô nhiễm môi trường nghiêm trọng (Nguyen Sang, 2016). Các nhà khoa học đã ước tính rằng ngành chăn nuôi làm tăng 18\% lượng khí nhà kính gây ra biến đổi khí hậu toàn cầu, thậm chí còn lớn hơn cả ô nhiễm không khí do ngành vận tải gây ra (WHO, 2005). Hiện nay, nghiên cứu về than sinh học ở Việt Nam chủ yếu nhằm cải tạo đất trong nông nghiệp (Doan và nnk., 2015; Mohammadi và nnk.,2017; Ngo Thi Phuong và nnk., 2013), loại bỏ amoni trong nước (Vu Thi Mai và nnk., 2016), loại bỏ thuốc trừ sâu propoxur (Nguyễn khởi nghĩa và nnk., 2015) ... Tuy nhiên, các nghiên cứu về than sinh học để loại bỏ ô nhiễm hữu cơ hoặc vi sinh vật gây bệnh trong nước thải chăn nuôi vẫn chưa được nghiên cứu nhiều. Tận dụng điểm mạnh của một nước nông nghiệp, thu hồi các phế phẩm nông nghiệp, chế biến, cải tạo và xử lý biến chúng thành các vật liệu có khả năng ứng dụng trong xử lý môi trường là một trong những việc làm thiết thực giúp tiết kiệm chi phí nguyên nhiên liệu, đồng thời góp phần bảo vệ môi trường. Vì vậy, mục tiêu bước đầu của nghiên cứu này là tận dụng phế phẩm bã cà phê để tổng hợp than sinh học bằng phương pháp nhiệt phân chậm nhằm xử lý ô nhiễm hữu cơ (COD và TSS) trong nước thải chăn nuôi.

\section{Phương pháp nghiên cứu}

\subsection{Phương pháp tổng hợp vật liệu và xác định đặc trung cấu trúc vật liệu}

Bốn loại vật liệu than sinh học CF1 (500\%/0,5 giờ); CF2 (500\%/1,5 giờ); CF3 (500\%/3 giờ); CF4 (500\% $/ 6$ giờ) trong nghiên cứu này được tổng hợp theo quy trình của (Cui và nnk., 2015) nhờ quá trình nhiệt phân chậm ở các điều kiện thời gian và nhiệt độ khác nhau. Đặc trưng vật liệu được xác định bằng các kỹ thuật: hiển vi điện tử quét (SEM - Scanning Electron Microscope), phổ tán sắc năng lượng tia X (EDX - Energy-dispersive X-ray) và xác định diện tích bề mặt, lỗ xốp của vật liệu (BET - Brunauer-Emmett-Teller) tại Viện Kỹ thuật Nhiệt đới - Viện Hàn lâm Khoa học và Công nghệ Việt Nam.

\subsection{Thiết kếthí nghiệm}

Bốn loại vật liệu CF1, CF2, CF3 và CF4 được rửa sạch qua nước cất, sấy khô ở $105^{\circ} \mathrm{C}$ trong 10 giờ và được đánh giá khả năng hấp thụ theo thời gian với quy trình của (Trinh Thi Thu Huong và nnk., 
2015) như sau: cân $1 \mathrm{~g}$ than sinh học cho vào bình tam giác nút nhám chứa $100 \mathrm{~mL}$ nước thải chăn nuôi, khuấy đều trên bếp khuấy từ với tốc độ 150 vòng/phút ở các khoảng thời gian 1,4 và 8 giờ. Xác định khả năng xử lý COD và TSS của các mẫu vật liệu song song với mẫu đối chứng không bổ sung than sinh học.

\subsection{Phương pháp xác định khả năng hấp thụ của vật liệu}

Để xác định khả năng hấp thụ của các mẫu vật liệu than sinh học, mẫu nước thải chăn nuôi ban đầu được lấy ở huyện Thanh Trì, Hà Nội và chuyển đến Phòng thí nghiệm. Mẫu nước thải sẽ phân tích ngay thông số COD và TSS để xác định giá trị ô nhiễm ban đầu. $100 \mathrm{~mL}$ nước thải chăn nuôi sẽ được lọc qua các cột với bộ lọc nhồi $4 \mathrm{~g}$ than sinh học CF1-CF4 với các khoảng thời gian phản ứng khác nhau (thay đổi từ $0 \mathrm{~h}, 1 \mathrm{~h}, 4 \mathrm{~h}$ và $8 \mathrm{~h}$, mẫu nước thải sau phản ứng sẽ được phân tích COD và TSS để đánh giá khả năng xử lý ô nhiễm.

Khả năng hấp thụ $\mathrm{q}_{\mathrm{e}}(\mathrm{mg} / \mathrm{g})$ tại thời điểm cân bằng được xác định theo công thức (Abdelkreem, 2013):

$$
q_{e}=\left(C_{o}-C_{e}\right) \cdot V / m
$$

Hiệu suất hấp thụ $\mathrm{H}(\%)$ tại thời điểm cân bằng được xác định theo công thức (Figueiredo và nnk., 2017):

$$
H=\left(C_{o}-C_{e}\right) / C_{0 .} 100(\%)
$$

Trong đó $\mathrm{q}_{\mathrm{e}}$ là khả năng hấp thụ ở trạng thái cân bằng $(\mathrm{mg} / \mathrm{g}) ; \mathrm{C}_{0}$ : nồng độ ban đầu $(\mathrm{mg} / \mathrm{L}) ; \mathrm{C}_{\mathrm{e}}$ : nồng độ ở trạng thái cân bằng $(\mathrm{mg} / \mathrm{L})$; $\mathrm{V}$ : thể tích dung dịch (L); m: khối lượng vật liệu hấp thụ (g).

Thông số COD trong mẫu nước thải được phân tích theo TCVN 6491: 1999 (ISO 6060:1989): Chất lượng nước - xác định nhu cầu oxi hóa học

Thông số TSS trong mẫu nước thải được phân tích theo TCVN 6625:2000 (ISO 11923:1997): Chất lượng nước - xác định chất rắn lơ lửng bằng phương pháp lọc.

\subsection{Xử lý thống kê số liệu}

Số liệu trong nghiên cứu này được thống kê và xử lý bằng các phần mềm GraphPad 6; Excel 2010 với ý nghĩa xác suất thống kê $\rho<0,05$.

\section{Kết quả và thảo luận}

\subsection{Kết quả xác định đặc trưng cấu trúc vật liệu than sinh hoc đã tổng hợp}

Đặc trưng cấu trúc vật liệu của bốn loại than sinh học CF1-CF4 được liệt kê trong Bảng 1. Hàm lượng tro của tất cả các chất hấp thụ này khá cao (>25\%), đặc biệt là CF4 (31,25\%). Đây cũng là mẫu có diện tích bề mặt BET lớn nhất trong bốn mẫu than sinh học được thử nghiệm. Diện tích bề mặt BET của các mẫu còn lại khá thấp, dao động từ 0,7917 đến $1,2466 \mathrm{~m}^{2} / \mathrm{g}$.

Đặc trưng cấu trúc bề mặt vật liệu các mẫu than sinh học CF1-CF4 cũng được xác định bằng phương pháp chụp SEM, kết quả thể hiện trong Hình 1 và Hình 2 . Ảnh chụp SEM cấu trúc vật liệu tương đồng với ghi nhận của các nghiên cứu về vật liệu than sinh học đã công bố (Cui và nnk., 2015; Liu và nnk., 2015). Kết quả chụp SEM ở các Hình 4,5 và 6 cho thấy, bề mặt vật liệu của mẫu đối chứng và mẫu thử nghiệm có sự khác biệt rõ rệt. Mẫu đối chứng (CF0, bã cà phê ban đầu) có bề mặt vật liệu đặc, không rõ các thớ sợi cellulose. Ngược lại ở các mẫu thử nghiệm (CF1-CF4) bề mặt vật liệu gồ ghề, có cấu trúc sợi rõ ràng, khoảng cách giữa các lỗ rỗng tương ứng với mặt phẳng mạng tinh thể (Cui và nnk., 2015). Bề mặt vật liệu gồ ghề, xù xì và có những đường vân nhỏ có thể đã xuất hiện trong quá trình nhiệt phân hoặc là một phần đặc tính của nguyên liệu thô (Liu và nnk., 2015). Đặc tính này sẽảnh hưởng mạnh đến tính chất hấp thụ của chúng (Cui và nnk., 2015; Liu và nnk., 2015). Điều này cho thấy, bã cà phê sau khi được tro hóa có khả năng hấp thụ tốt hơn so với vật liệu thô ban đầu.

\begin{tabular}{|c|c|c|c|c|c|c|}
\hline $\begin{array}{c}\text { Than sinh } \\
\text { học }\end{array}$ & $\begin{array}{c}\text { Thời gian và nhiệt } \\
\text { độ nhiệt phân }\end{array}$ & $\begin{array}{c}\text { Hàm lượng tro } \\
(\%)\end{array}$ & $\begin{array}{c}\text { Diện tích bề mặt } \\
\text { BET }\left(\mathrm{m}^{2} / \mathrm{g}\right)\end{array}$ & \multicolumn{2}{|c|}{ Hàm lượng nguyên tố bề mặt } \\
\cline { 5 - 7 } & - & - & $7 \%)$ & $0(\%)$ & $\mathrm{N}(\%)$ \\
\hline CF0 & - & - & 0,7917 & 84,65 & 9,98 & 7,13 \\
\hline CF1 & $500^{\circ} \mathrm{C} / 0,5 \mathrm{~h}$ & 28,6 & 0,8564 & 84,61 & 9,06 & 4,82 \\
\hline CF2 & $500^{\circ} \mathrm{C} / 1,5 \mathrm{~h}$ & 29,6 & 1,2466 & 83,29 & 9,53 & 4,06 \\
\hline CF3 & $500^{\circ} \mathrm{C} / 3 \mathrm{~h}$ & 30,94 & 1,5016 & 90,61 & 6,86 & 1,41 \\
\hline CF4 & $500^{\circ} \mathrm{C} / 6 \mathrm{~h}$ & 31,25 & \multicolumn{3}{|c}{} \\
\hline
\end{tabular}




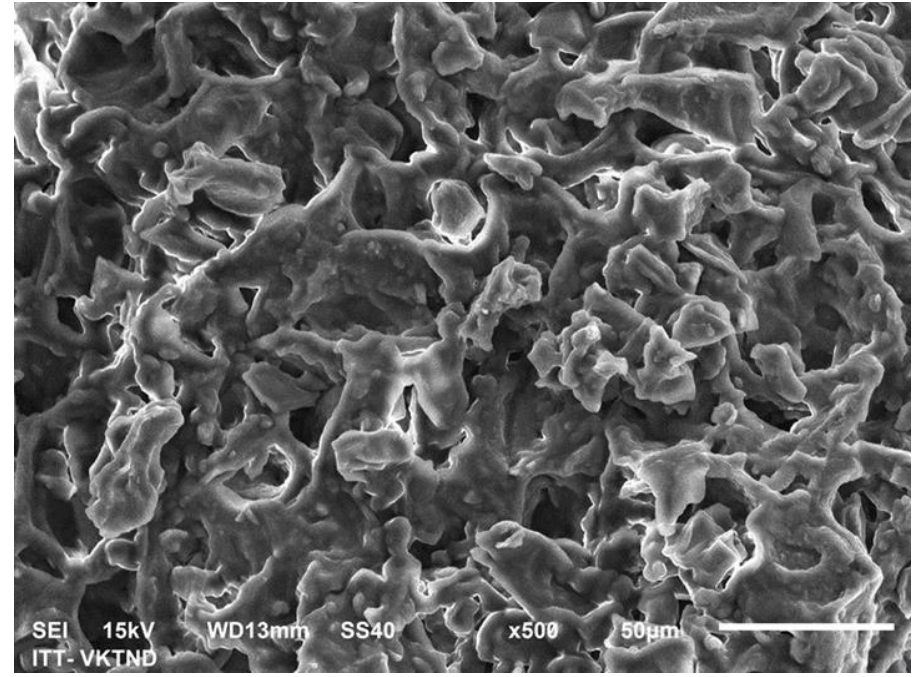

Hình 1. Kết quả chụp SEM mẫu CFO (bã cà phê chưa tro hóa).
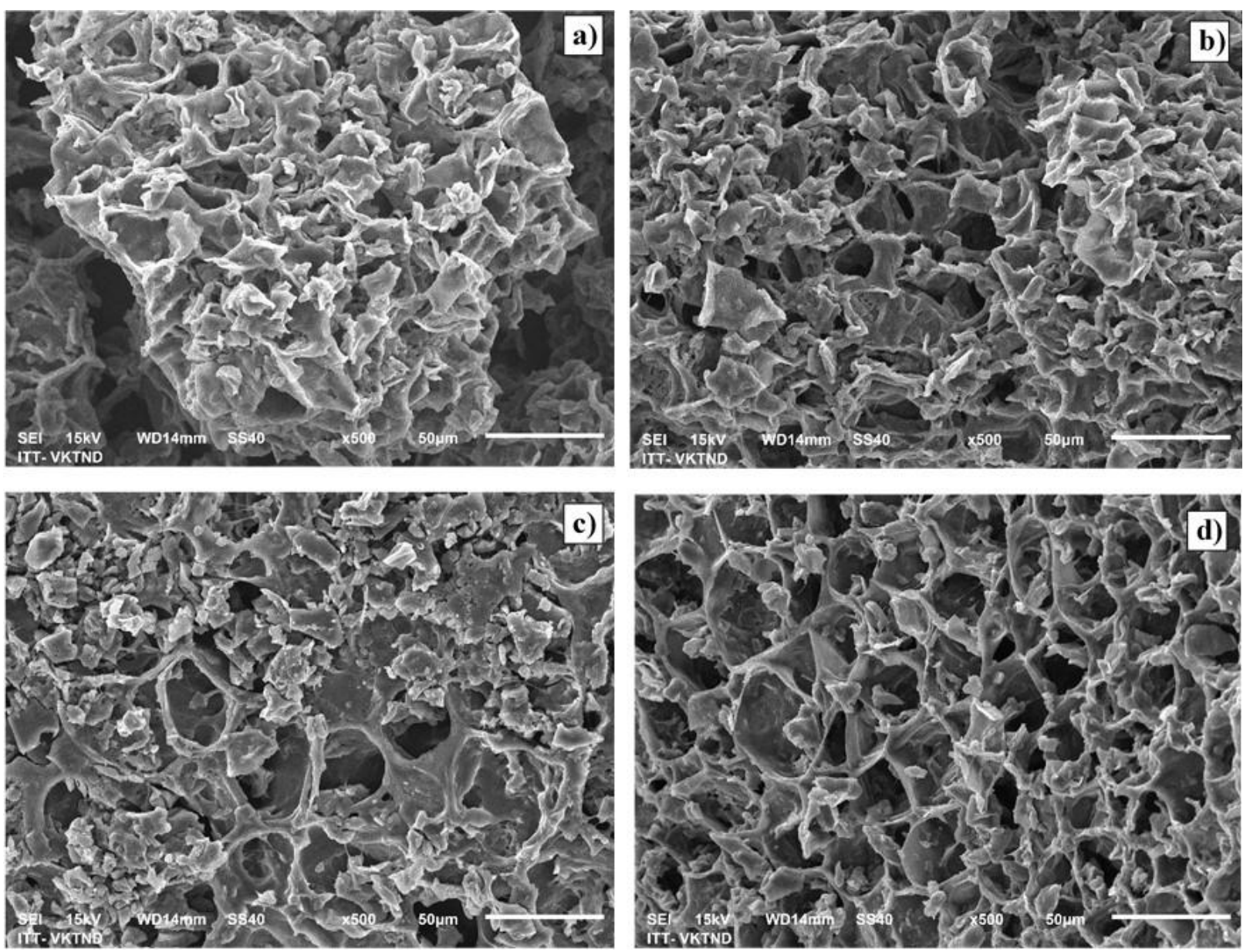

Hình 2. Kết quả chụp SEM các mẫu vật liệu than sinh học: CF1 (a); CF2 (b); CF3 (c) và CF4 (d).

Tương tự như kết quả SEM, thành phần hóa học của mẫu được xác định bằng phổ phân tán năng lượng EDX. Trong mẫu vật liệu than sinh học thì phần trăm nguyên tố $\mathrm{C}$ trong vật liệu đã tổng hợp là một trong những tiêu chí quan trọng quyết 


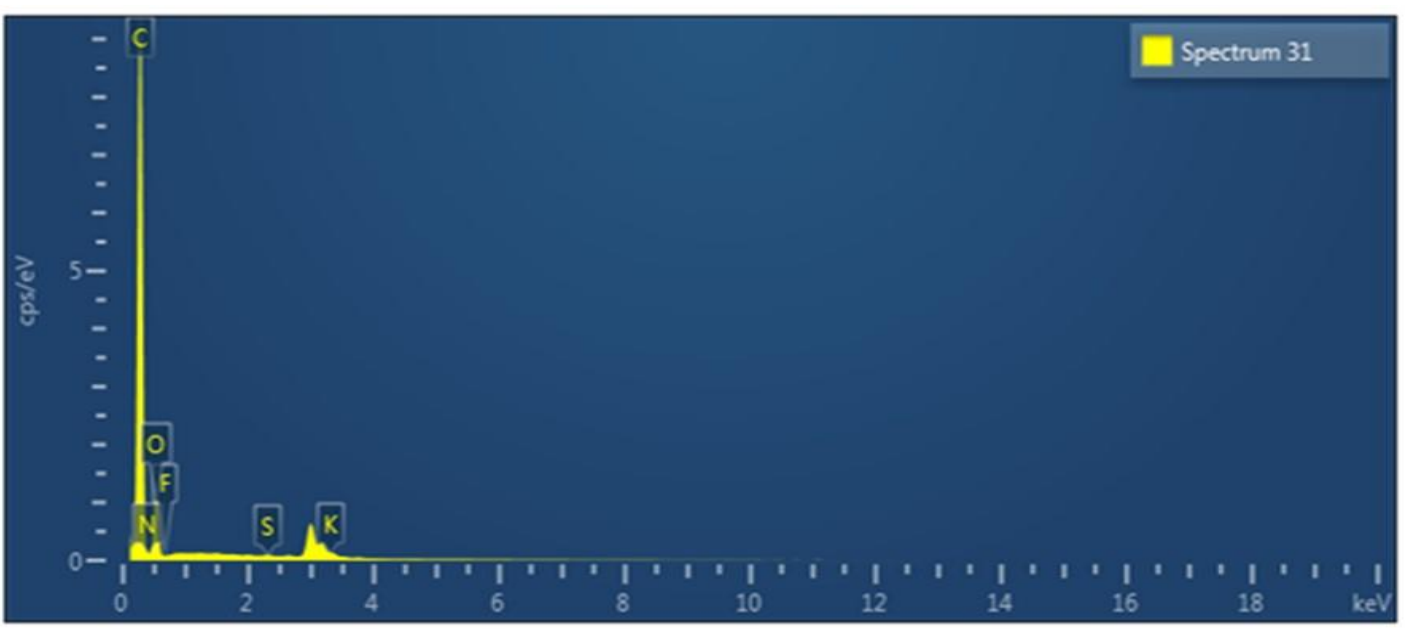

Hình 3. Kết quả đo EDX mẫu CFO (bã cà phê chưa tro hóa).
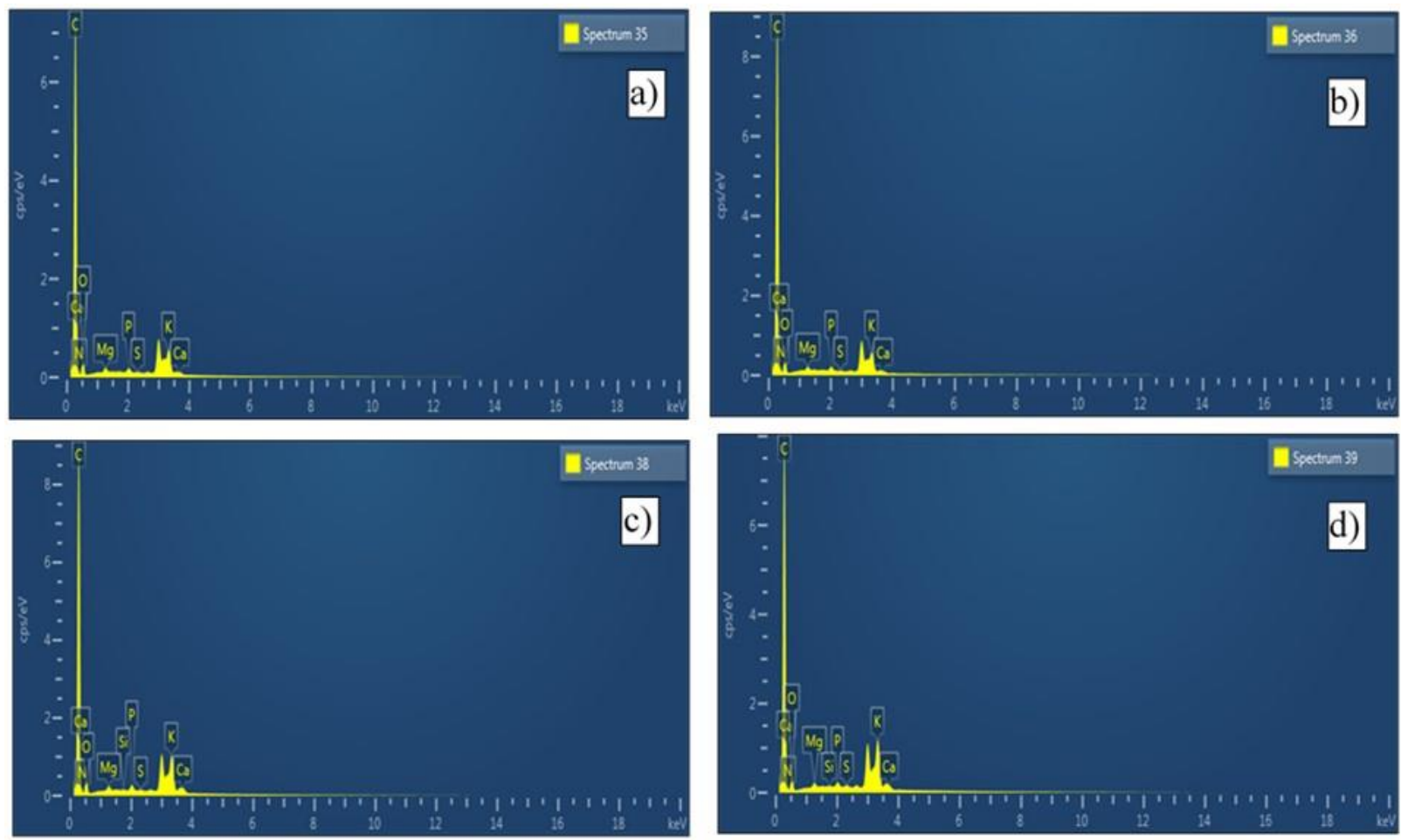

Hình 4. Kết quả đo EDX mẫu than sinh học: CF1 (a); CF2 (b); CF3 (c) và CF4 (d)

định đến khả năng hấp thụ của vật liệu. Kết quả đo EDX các mẫu vật liệu thể hiện trong Hình 3 và 4.

Phân tích nguyên tố chỉ ra rằng có một lượng lớn hàm lượng $\mathrm{C}$ trong cả bốn mẫu than sinh học (hơn 80\%). Hàm lượng các nguyên tố bề mặt trong Bảng 2 cho thấy than sinh học CF4 chứa $90,61 \%$ C trên bề mặt của nó, trong khi CF3 có hàm lượng $C$ ít nhất $(83,29 \%)$. Tuy nhiên, mẫu đã tro hóa có hàm lượng $\mathrm{C}$ cao hơn so với mẫu vật liệu thô ban đầu. Hàm lượng $\mathrm{C}$ trong mẫu đối chứng ghi nhận là $74,15 \%$ C so với mẫu thử nghiệm có giá trị lần lượt là 84,65\% (CF1); 84,61\% (CF2); 83,29\% (CF3) và 90,61\% (CF4). Theo Cui và nnk. (2015), các nhóm liên kết chức năng như $-\mathrm{OH}, \mathrm{C}-\mathrm{H}, \mathrm{C}=\mathrm{O}, \ldots$ có ảnh hưởng mạnh đến khả năng hấp thụ ion (Cui và nnk., 2015). Trên bề mặt vật liệu carbonate nếu có nhiều nhóm hydroxyl và carboxyl sẽ đóng vai trò quan trọng trong trao đổi ion và hiệu quả hấp thụ các chất ô nhiễm phụ thuộc vào các nhóm cực trên bề mặt vật liệu này (Hirata và nnk., 2002). Vì vậy, với hàm lượng $\mathrm{C}$ ghi nhận trên $80 \%$ sau khi tro hóa đã chứng minh rằng, các mẫu than sinh học từ vật liệu 
bã cà phê có khả năng hấp thụ và xử lý cao các chất ô nhiễm.

\subsection{Kết quả phân tích và đánh giá hiệu suất xử lý COD của than sinh học}

Mẫu nước thải chăn nuôi chưa xử lý được lấy tại trang trại lợn thuộc xã Vạn Phúc, huyện Thanh Trì, Hà Nội. Kết quả phân tích hàm lượng COD và TSS trong mẫu ban đầu thể hiện trong Bảng 2 cho thấy, cả hai thông số đều vượt quy chuẩn cho phép của QCVN 62:2016/BTNMT: quy chuẩn kỹ thuật quốc gia về nước thải chăn nuôi nhiều lần.

Bảng 2. Kết quả phân tích hàm lượng $\mathrm{COD}_{0}$ và TSS trong mẫu chưa xử lý.

\begin{tabular}{|c|c|c|c|c|}
\hline $\begin{array}{c}\text { Thông } \\
\text { số }\end{array}$ & Đơn vị & $\begin{array}{c}\text { Kết } \\
\text { quả }\end{array}$ & $\begin{array}{c}\text { QCVN 62:2016/ } \\
\text { BTNMT }\end{array}$ & $\begin{array}{c}\text { Số lần } \\
\text { vượt }\end{array}$ \\
\hline $\mathrm{COD}_{0}$ & $\mathrm{mg} / \mathrm{L}$ & 7800 & 300 & 26 \\
\hline $\mathrm{TSS}_{0}$ & $\mathrm{mg} / \mathrm{L}$ & 270 & 150 & 1,8 \\
\hline
\end{tabular}

Để đánh giá khả năng xử lý ô nhiễm của vật liệu, thí nghiệm hấp thụ đã được tiến hành. Bốn vật liệu than sinh học được đánh giá khả năng hấp thụ COD ở các khoảng thời gian phản ứng lần lượt là 0 (COD0); 1 (COD1); 4 (COD4) và 8 giờ (COD8) (Hình 5). Kết quả phân tích ở Hình 5 cho thấy, hàm lượng COD trong mẫu nước thải chăn nuôi sau xử lý giảm đáng kể so với mẫu đối chứng (CF0). Trong đó, mẫu vật liệu CF3 có khả năng loại bỏ COD cao nhất, giá trị COD sau thời gian xử lý 8 giờ ghi nhận là $280 \mathrm{mg} / \mathrm{L}$ so với mẫu đối chứng có hàm lượng COD ban đầu là $7800 \mathrm{mg} / \mathrm{L}$. Để đánh giá khả năng xử lý nước thải chăn nuôi, hiệu suất xử lý và hàm lượng hấp thụ của bốn loại

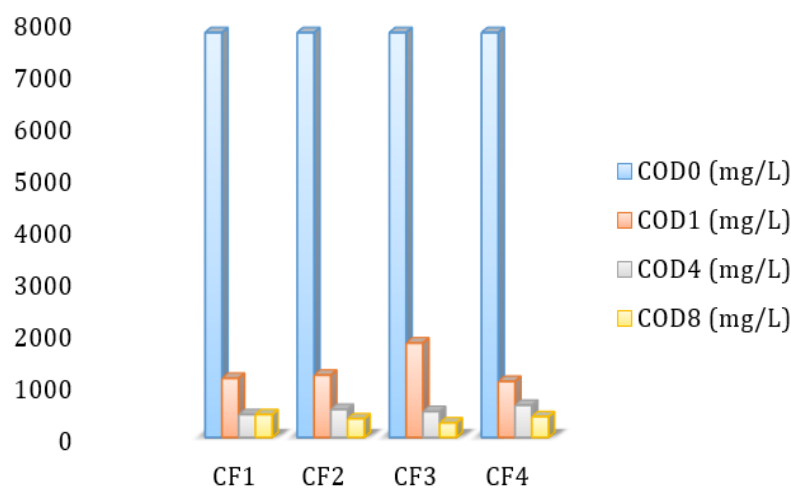

Hình 5. Kết quả xử lý COD của bốn loại vật liệu. vật liệu so với mẫu đối chứng đã được tính toán và thể hiện trong Bảng 3 và 4 .

Bảng 3. Hiệu suất xử lý COD của các vật liệu than sinh họ ở các khoảng thời gian khác nhau.

\begin{tabular}{|c|c|c|c|c|}
\hline \multicolumn{5}{|c|}{$H(\%)$} \\
\hline & CF1 & CF2 & CF3 & CF4 \\
\hline COD1h & 85,38 & 84,62 & 76,67 & 86,15 \\
\hline COD 4h & 94,36 & 93,08 & 93,59 & 92,05 \\
\hline COD 8h & 94,36 & 95,38 & 96,41 & 94,87 \\
\hline
\end{tabular}

Bảng 4. Hàm lượng hấp thụ COD của các vật liệu than sinh học ở các khoảng thời gian khác nhau.

\begin{tabular}{|c|c|c|c|c|}
\hline \multicolumn{5}{|c|}{$Q_{e}$ (mg/g) } \\
\hline & CF1 & CF2 & CF3 & CF4 \\
\hline COD1h & 166,5 & 165 & 149,5 & 168 \\
\hline COD 4h & 184 & 181,5 & 182,5 & 179,5 \\
\hline COD 8h & 184 & 186 & 188 & 185 \\
\hline
\end{tabular}

Kết quả ở Bảng 3 và 4 cho thấy, hiệu suất xử lý và hàm lượng hấp thụ COD của bốn loại vật liệu khác nhau là khác nhau và ở các khoảng thời gian xử lý khác nhau hiệu suất và hàm lượng hấp thụ cũng khác nhau. Trong đó, hiệu suất và hàm lượng hấp thụ của mẫu vật liệu CF3 ghi nhận cao nhất $96,41 \%$ và $188 \mathrm{mg} / \mathrm{g}$ ở thời gian xử lý 8 giờ, mẫu vật liệu than sinh học CF3 ghi nhận giá trị thấp nhất là $76,67 \%$ và $149,5 \mathrm{mg} / \mathrm{g}$ sau thời gian 1 giờ. Kết quả này cho thấy, thời gian xử lý càng dài thì hiệu suất xử lý của than sinh học càng cao. Như vậy, có thể thấy thời gian tro hóa của vật liệu và thời gian lưu để xử lý nước thải có ảnh hưởng đến hiệu suất xử lý của vật liệu. Bã cà phê được tro hóa ở $^{2} 500^{\circ} \mathrm{C}$ trong 1,5 giờ và thời gian lưu nước thải là 8 giờ sẽ đạt được hiệu quả cao nhất.

\subsection{Kết quả phân tích và đánh giá hiệu suất xử lý TSS của than sinh học}

Tương tự như thông số COD, bốn loại vật liệu than sinh học đã tổng hợp cũng được đánh giá khả năng xử lý tổng chất rắn lơ lửng (TSS) ở $0,1,4$ và 8 giờ. Kết quả thể hiện trong Hình 6 cho thấy, hàm lượng TSS xử lý bằng các dạng vật liệu than sinh học (CF1-CF4) đã giảm đáng kể so với mẫu đối chứng. Trong đó, hàm lượng TSS thử nghiệm với mẫu vật liệu CF3 giảm thấp nhất, giá trị TSS sau thời gian xử lý 8 giờ giảm còn $13 \mathrm{mg} / \mathrm{L}$ so với mẫu đối chứng có hàm lượng TSS ban đầu là $270 \mathrm{mg} / \mathrm{L}$. Mẫu vật liệu than sinh học CF3 có khả năng loại bỏ 
TSS thấp nhất, giảm còn $87 \mathrm{mg} / \mathrm{L}$ so với mẫu đối chứng sau thời gian xử lý 1 giờ. Tương tự, để đánh giá khả năng xử lý TSS trong nước thải chăn nuôi,

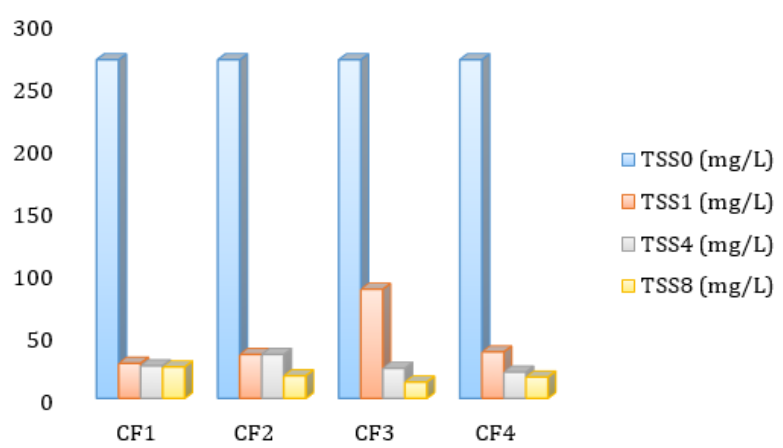

Hình 6. Kết quả xử lý TSS của bốn loại vật liệu.

hiệu suất xử lý và hàm lượng hấp thụ của bốn loại vật liệu so với mẫu đối chứng đã được tính toán và thể hiện trong Bảng 5 và 6 .

Bảng 5. Hiệu suất xử lý TSS của các vật liệu than sinh học ở các khoảng thò̀i gian khác nhau.

\begin{tabular}{|c|c|c|c|c|}
\hline \multicolumn{5}{|c|}{ H (\%) } \\
\hline & CF1 & CF2 & CF3 & CF4 \\
\hline TSS 1h & 89,63 & 87,04 & 67,78 & 86,30 \\
\hline TSS 4h & 90,37 & 87,04 & 91,11 & 92,22 \\
\hline TSS 8h & 90,74 & 93,33 & 95,19 & 93,70 \\
\hline
\end{tabular}

Bảng 6. Hàm lượng hấp thụ TSS của các vật liệu than sinh học ở các khoảng thòi gian khác nhau.

\begin{tabular}{|c|c|c|c|c|}
\hline \multicolumn{5}{|c|}{$\mathrm{Q}_{\mathrm{e}}$ (mg/g) } \\
\hline & CF1 & CF2 & CF3 & CF4 \\
\hline TSS 1h & 6,05 & 5,875 & 4,575 & 5,825 \\
\hline TSS 4h & 6,1 & 5,875 & 6,15 & 6,225 \\
\hline TSS 8h & 6,125 & 6,3 & 6,425 & 6,325 \\
\hline
\end{tabular}

Hiệu suất xử lý và hàm lượng hấp thụ ở Bảng 5 và 6 chỉ ra rằng, các loại vật liệu khác nhau có giá trị khác nhau ở các khoảng thời gian khác nhau. Trong đó, hiệu suất và hàm lượng hấp thụ của mẫu vật liệu CF3 ghi nhận cao nhất 95,19\% và 6,425 $\mathrm{mg} / \mathrm{g}$ ở thời gian xử lý 8 giờ và thấp nhất là $66,78 \%$ và 4,575 mg/g sau 1 giờ. Kết quả này cho thấy, thời gian xử lý quyết định đến hiệu suất xử lý của vật liệu.

Kết quả ghi nhận của nghiên cứu này phù hợp với một số nghiên cứu về than sinh học đã công bố trước đây (Cui và nnk., 2015; Deng và nnk., 2017; Gehan và nnk., 2015; Hirata và nnk., 2002; Liu và nnk., 2015). Tuy nhiên các nghiên cứu trước đây chủ yếu sử dụng than sinh học để xử lý ô nhiễm màu trong nước thải dệt nhuộm (Gehan và nnk., 2015; Hirata và nnk., 2002), hấp thụ thuốc trừ sâu (Liu và nnk., 2015) hay biến tính than sinh học với vật liệu nano bạc để diệt vi khuẩn gây bệnh (Cui và nnk., 2015). Nước thải chăn nuôi là loại nước thải có hàm lượng chất ô nhiễm hữu cơ cao, đặc biệt là nitơ và phốt pho nên việc xử lý gặp khá nhiều khó khăn và chưa được nghiên cứu nhiều. Hiệu suất xử lý các hợp chất ô nhiễm hữu cơ trong nước thải chăn nuôi thụ thuộc vào cấu trúc đặc trưng của vật liệu than sinh học (Deng và nnk., 2017). Than sinh học có cấu trúc hữu cơ bao gồm hai lớp: các lớp graphene xếp chồng lên nhau và cấu trúc thơm xen kẽ với lớp graphene làm cho các lớp vật liệu có bề mặt riêng lớn và dày đặc các lỗ xốp rỗng, giúp vật liệu tăng cường khả năng hấp thụ vật lý nên hiệu suất xử lý tăng cao (Deng và nnk., 2017). Với thí nghiệm hiện tại chỉ có chỉ tiêu TSS đạt tiêu chuẩn nước thải sau xử lý, thông số COD vần cao hơn từ 1,2 đến 1,46 lần so với $\mathrm{QCVN}$ 62:2016/BTNMT.

\section{Kết luận}

Nghiên cứu này đã khảo sát đặc trưng vật liệu và khả năng xử lý COD và TSS của 4 loại vật liệu than sinh học ở các điều kiện nhiệt phân khác nhau: $\mathrm{CF} 1\left(500^{\circ} \mathrm{C}\right.$ ở 0,5 giờ); $\mathrm{CF} 2\left(500^{\circ} \mathrm{C}\right.$ ở 1,5 giờ); $\mathrm{CF} 3\left(600^{\circ} \mathrm{C}\right.$ ở 0,5 giờ); $\mathrm{CF} 4\left(600^{\circ} \mathrm{C}\right.$ ở 1,5 giờ). Kết quả ghi nhận hiệu suất xử lý COD và TSS của bốn loại vật liệu khác nhau là khác nhau, trong đó mẫu vật liệu CF3 có khả năng loại bỏ COD và TSS cao nhất với hiệu suất và hàm lượng hấp thụ tương ứng lần lượt là 96,41\% và 95,19\%; 188 $\mathrm{mg} / \mathrm{g}$ và $6.425 \mathrm{mg} / \mathrm{g}$ ở thời gian xử lý 8 giờ, thấp nhất là $76,67 \%$ và $66,78 \% ; 149,5 \mathrm{mg} / \mathrm{g}$ và 4.575 $\mathrm{mg} / \mathrm{g}$ sau 1 giờ. Hàm lượng TSS đạt yêu cầu so với QCVN 62:2016/BTNMT - quy chuẩn kỹ thuật quốc gia về nước thải chăn nuôi, COD sau xử lý vẫn cao hơn quy chuẩn Việt Nam từ 1,2 đến 1,46 lần. Kết quả này cũng chỉ ra tiềm năng của than sinh học từ bã cà phê nhằm ứng dụng xử lý ô nhiễm hữu cơ trong nước thải.

\section{Lò̀i cảm ơn}

Nghiên cứu này được hoàn thành dưới sự hỗ trợ của học bổng Rosneft dành cho nghiên cứu khoa học sinh viên năm 2019. Tập thể tác giả xin chân thành cảm ơn Công ty Dầu khí Rosneft và 
Trường Đại học Mỏ - Địa chất đã tạo điều kiện để hoàn thành đề tài này.

\section{Tài liệu tham khảo}

Abdelkreem, M., (2013). Adsorption of Phenol from Industrial Wastewater Using Olive Mill Waste. APCBEE Procedia 5, 349-357

Chen, B., Zaiming, C., and Shaofang, L., (2011). A Novel Magnetic Biochar Efficiently Sorbs Organic Pollutants and Phosphate. Bioresource Technology 102(2), 716-723.

Cui, J., Yunhua, Y., Yonghui, H., and Fangbai, L., (2015). Rice Husk Based Porous Carbon Loaded with Silver Nanoparticles by a Simple and Cost-Effective Approach and Their Antibacterial Activity. Journal of Colloid and Interface Science 455, 117-24.

Deng, Y., Tao, Z., and Qiming, W., (2017). Biochar Adsorption Treatment for Typical Pollutants Removal in Livestock Wastewater: A Review. Engineering Applications of Biochar, 71-82.

Doan, T. T., Thiery, H. T., Cornelia, R., Jean, L. J., and Pascal, J., (2015). Impact of Compost, Vermicompost and Biochar on Soil Fertility, Maize Yield and Soil Erosion in Northern Vietnam: A Three Year Mesocosm Experiment. Science of the Total Environment 514, 147-54.

Figueiredo, M. K. K., Caldas, K. N. C., Nascimento, B. P., Schroeder, P., and Romeiro, G. A., (2017). Use of biochar obtained from coffee grounds as adsorbent of dyes and solid biofuel. Revista Eletrônica em Gestão, Educação e Tecnologia Ambiental Santa Maria 21, 92-103.

Gehan, M. K., Tolba, Nasser, A. M., Barakat, A. M., Bastaweesy, E. A., Ashour, Hak, Y. K., Wael A., Mohamed H. E. N., Salem, S., and Al-Deyab., (2015). Effective and Highly Recyclable Nanosilica Produced from the Rice Husk for Effective Removal of Organic Dyes. Journal of Industrial and Engineering Chemistry 9, 13445.

Hirata, M., Kawasaki, N., Nakamura, T., Matsumoto, K., Kabayama, M., Tamura, M., and Tanada, S., (2002). Adsorption of Dyes onto Carbonaceous Materials Produced from Coffee Grounds by Microwave Treatment. Journal of Colloid and Interface Science 254(1), 17-22.
Johanne Lehmann,. (2007). A Handful of Carbon. Nature 447(7141), 143-44.

Kizito, S., Wu, S., Kirui, W.K., Lei, M., Lu, Q., Bah, H., and Dong, R., (2015). Evaluation of Slow Pyrolyzed Wood and Rice Husks Biochar for Adsorption of Ammonium Nitrogen from Piggery Manure Anaerobic Digestate Slurry. Science of the Total Environment 505, 102-12.

Liu, N., Charrua, A. B., Weng, C. H., Yuan, X., and Ding, F., (2015). Characterization of Biochars Derived from Agriculture Wastes and Their Adsorptive Removal of Atrazine from Aqueous Solution: A Comparative Study. Bioresource Technology 198, 55-62.

Mohammadi, A., Cowie, A. L., Mai, T. L. A., Brandão, M., Rosa, R. A., Kristiansen, P., and Joseph, S., (2017). Climate-Change and Health Effects of Using Rice Husk for Biochar-Compost: Comparing Three Pyrolysis Systems. Journal of Cleaner Production 162, 260-72.

Ngo, P. T., Rumpel, C., Ngo, Q. A., Alexis, M., Vargas, G. V., Gil, M de la L. M., Dang, D. K., and Jouquet, P., (2013). Biological and Chemical Reactivity and Phosphorus Forms of Buffalo Manure Compost, Vermicompost and Their Mixture with Biochar. Bioresource Technology 148: 401-408.

Nguyễn Khởi Nghĩa, Nguyễn Thị Kiều Oanh, Đỗ Hoàng Sang and Lâm Tử Lăng., (2015). Khả Năng Cố Định vi Khuẩn Phân Hủy Hoạt Chất Thuốc Trừ Sâu Propoxur (Paracoccus SP. P237) Của Biochar. Tạp chí Khoa học Trường Đại học Cần Tho 38 (2), 88-94

Nguyen Sang, (2016). Report of Research on the Use of Animal Waste Water by Biological Methods Combined with Membrane Filtration, Hanoi National University - Hanoi University of Science.

Pan, J., Jun, J., and Renkou, X., (2013). Adsorption of Cr(III) from Acidic Solutions by Crop Straw Derived Biochars. Journal of Environmental Sciences (China) 25(10), 1957-1965.

Sumalinog, D. A. G., Sergio, C. C., and Mark, D. G. de L., (2018). Evaluation of the Effectiveness and Mechanisms of Acetaminophen and Methylene Blue Dye Adsorption on Activated Biochar 
Derived from Municipal Solid Wastes. Journal of Environmental Management 210, 255-262.

TCVN 6491: 1999 (ISO 6060:1989) - Chất lượng nước - xác định nhu cầu oxi hóa học

TCVN 6625:2000 (ISO 11923:1997): Chất lượng nước - xác định chất rắn lơ lửng bằng phương pháp lọc.

Trịnh Thị Thu Hương, Vũ Đức Thao. (2015). Nghiên Cứu Sử Dụng than Bã Cà Phê Để Xử Lý Màu và Chất Hưu Cơ Trong Nước Thải Dệt Nhuộm. Tạp chí phân tích Hóa, Lý và Sinh học 20(2), 76-82.

Truong Hong, (2018). Report of 'Area and Output of Coffee in the World, Western Highlands Agriculture and Forestry Science Institute, 2018.
Tsai., and Wen Tien. (2017). The Potential of Pyrolysing Exhausted Coffee Residue for the Production of Biochar. Handbook of Coffee Processing By-Products. Sustainable Applications, 299-322.

Vũ Thị Mai and Trịnh Văn Tuyên, (2016). Nghiên Cứu Khả Năng Xử Lý Amoni Trong Môi Trường Nước Của than Sinh Học Từ Lõi Ngô Biến Tính Bằng $\mathrm{H} 3 \mathrm{PO} 4$ và $\mathrm{NaOH}$. Tạp chí Khoa học Đại học Quốc gia Hà Nội: Các Khoa học Trái đất và Môi trường 32(1S), 274-81.

WHO Report, 2005.

Yang, Y., Lin, X., Wei, B., Zhao, Y., and \& Wang, J., (2014). Evaluation of Adsorption Potential of Bamboo Biochar for Metal-Complex Dye: Equilibrium, Kinetics and Artificial Neural Network Modeling. International Journal of Environmental Science and Technology 11(4), 1093-1100. 